\title{
Effect of Curing Temperature and Architectural (Monolayer and Bilayer) of Hybrid Films Modified with Polyethylene Glycol for the Corrosion Protection on Tinplate
}

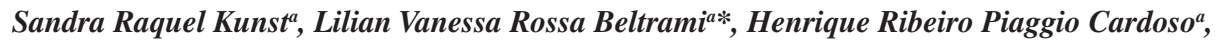 \\ Maria Rita Ortega Veja ${ }^{a}$ Estela Knopp Kerstner Baldin ${ }^{a}$,Tiago Lemos Menezes ${ }^{b}$, Célia de Fraga Malfatti ${ }^{a}$ \\ ${ }^{a}$ Laboratório de Pesquisa em Corrosão - LAPEC, Federal University of Rio Grande do Sul - UFRGS, \\ Avenida Bento Gonçalves, 9500, Porto Alegre, RS, Brazil \\ ${ }^{b}$ Laboratório de Corrosão, Proteção e Reciclagem de Materiais - LACOR, Federal University of Rio \\ Grande do Sul - UFRGS, Avenida Bento Gonçalves, 9500, Porto Alegre, RS, Brazil
}

Received: March 26, 2014; Revised: June 24, 2014

\begin{abstract}
Hybrid films obtained by a sol-gel process are based on two important reactions: hydrolysis and condensation. The condensation reaction is influenced by the curing temperature, since it induces the development of the intrinsic properties of the gel. The aim of this work is to coat tinplate, a substrate widely used in the packaging industry, with monolayered and bilayered hybrid films modified with polyethylene glycol and obtained through dip-coating. The results showed that the bilayered hybrid film obtained at $60^{\circ} \mathrm{C}$ had a higher layer thickness, and the best performance in the electrochemical assays, as well as the most hydrophobic character, in relation to the other samples. For the monolayered systems, the $90^{\circ} \mathrm{C}$-cured system showed a lower layer thickness; however, this system showed a more compact, uniform and less porous layer, and presented better electrochemical impedance results, in comparison with the $60^{\circ} \mathrm{C}$-cured samples.
\end{abstract}

Keywords: tinplate, temperature, bilayered systems, monolayered systems

\section{Introduction}

Tinplate is a thin low-carbon mild steel sheet, cold reduced, coated on both sides with pure electrolytic tin, linking the strength and formability of the steel with the corrosion resistance and weldability of the $\operatorname{tin}^{1,2}$. Tinplate is largely used in food packaging, being ideally suited for this purpose since it is non-toxic, light in weight, strong, and corrosion-resistant ${ }^{3}$.

The resulting coating has the following stratified structure from bottom to top: an $\mathrm{FeSn}_{2}$ alloy developed from flow-brightening which protects the steel against galvanic corrosion by oxidant species; and a free tin layer that determines the durability when acting as a sacrificial anode ${ }^{4}$.

Regarding the tinplate quality, the presence of tin oxides on the surface is remarkable, since they affect the metallic sheet appearance, weldability and capacity of being coated with organic films ${ }^{5}$. Currently, packaging is submitted to a chromate-based surface treatment, for it offers excellent corrosion resistance ${ }^{6,7}$. Nevertheless, nontoxic pre-treatments have been developed to substitute the chromatization process ${ }^{8-10}$. Among these alternatives, hybrid organic-inorganic films are found ${ }^{11}$.

Hybrid films are constituted by the combination of two compounds, organic and inorganic, which, normally, have complementary properties and give raise to materials with very different properties from those of their precursors ${ }^{12}$. Those materials are extremely homogeneous, since their mixture occurs at a molecular level ${ }^{6}$. Organic-inorganic hybrid films obtained through a sol-gel process have the

*e-mail: lvrossa@yahoo.com.br advantage of being processed at low temperatures. For this reason there is neither solvent volatilization nor chemical species degradation ${ }^{13,14}$.

On the other hand, hybrid films obtained through the sol-gel method are not completely efficient as the films are not thick enough and tend to be cracked. In this sense, plasticizers, like polyethylene glycol ${ }^{15}$ or polymethyl methacrylate ${ }^{16}$, are used, with the purpose of increasing the layer thickness and the sol viscosity, or of enhancing the molecular flexibility and mobility to obtain uncracked films which can be submitted to mechanical deformation without failure. Additionally, it is recommended to obtain coatings with a high thickness layer in order to promote efficient barrier properties between the substrate and the environment. The increase in the thickness can be achieved in two ways: first, it is possible to increase the number of layers, but a limit must be observed in order to avoid delamination problems ${ }^{17}$; secondly, the sol viscosity can be increased, via temperature modification, however, in this case, the kinetics of the hydrolysis and condensation reactions varies and could induce modifications in the intrinsic properties of the gel ${ }^{18}$.

Pan et al. ${ }^{19}$ evaluated the performance of silane films in different curing temperatures and concluded that a higher curing temperature accelerates the hydrolysis and condensation, leading to denser films with a better water barrier performance.

The aim of this work is to coat tinplate with a hybrid film obtained through a sol process, constituted of the following alkoxide precursors: 3-(trimethoxysilylpropyl) methacrylate 
(TMSPMA) and tetraethoxysilane (TEOS), with addition of $0.01 \mathrm{M}$ cerium nitrate and the plasticizer polyethylene glycol at a concentration of $20 \mathrm{~g} . \mathrm{L}^{-1}$. The films were obtained by dip-coating process, applying monolayer and bilayer. The films were cured at different temperatures $\left(60^{\circ} \mathrm{C}\right.$ and $\left.90^{\circ} \mathrm{C}\right)$ for 20 minutes.

\section{Experimental Procedures}

\subsection{Surface preparation}

Tinplates with dimensions of $20 \times 40 \mathrm{~mm}$ were obtained from an industrial sheet, rinsed with acetone and dried. Then, the plates were degreased by a $10 \mathrm{~min}$ immersion in neutral detergent at $70^{\circ} \mathrm{C}$, washed and dried.

\subsection{Elaboration of hybrid films}

The hydrolysis reactions were conducted with hybrid film silane precursors (TMSPMA) 3-(trimethoxysilylpropyl) methacrylate $\left(\mathrm{C}_{10} \mathrm{H}_{20} \mathrm{SiO}_{5}\right)$ and (TEOS) tetraethoxysilane $\left(\mathrm{C}_{8} \mathrm{H}_{20} \mathrm{SiO}_{4}\right)$ with the addition of cerium nitrate in a concentration of $0.01 \mathrm{M}$. Ethanol and water were used as solvents. PEG 1500 was added in the formulation of the sol, at a concentration of 20 g.L. $\mathrm{L}^{-1}$. In addition, a sample without plasticizer was studied. The hydrolysis time was 24 hours. The application of hydrolyzed hybrid solutions was performed by dip-coating process, with a removal rate of $10 \mathrm{~cm} \cdot \mathrm{min}^{-1}$ and a permanence of 5 minutes in the solution. The films were obtained by dip-coating process, applying one or two layers to obtain monolayered and bilayered systems, and cured at two different temperatures, $60^{\circ} \mathrm{C}$ and $90^{\circ} \mathrm{C}$, for 20 minutes. A description of the samples used is presented on Table 1, and the protocol for the sol preparation as well as for the coatings is detailed on the flow chart (Figure 1).

\subsection{Experimental techniques}

The morphological characterization was carried out by using Scanning Electron Microscopy (SEM), performed in a JEOL 6060 device, with an acceleration voltage of $20 \mathrm{kV}$. The samples were observed in top view and in cross-section to determine the layer thickness.

The wettability of the hybrid films was determined by the contact angle measurement from the sessile drop method using equipment developed by the Research Laboratory of Corrosion (LAPEC) of UFRGS. The contact angle was determined by image analysis software.

The infrared spectroscopy (FTIR) measurements were performed on a spectrophotometer Spectrum ASCII 100. The measurements were performed with the beam in the mid-infrared (4000-500 $\left.\mathrm{cm}^{-1}\right)$. The spectra were obtained from the films without a substrate (free-standing films). For this characterization, two different curing temperatures $\left(60^{\circ} \mathrm{C}\right.$ and $\left.90^{\circ} \mathrm{C}\right)$ for 20 minutes were used.

The corrosion performance of the coatings was evaluated by open circuit potential $\left(E_{\text {cor }}\right)$ monitoring and Electrochemical Impedance Spectroscopy (EIS) measurements in a $0.05 \mathrm{M} \mathrm{NaCl}$ solution. This concentration is sufficiently high to activate corrosion in a relatively short exposure time, but low enough to enable the effects of various acids to be determined. Kozhukharov et al. ${ }^{20}$ also used $0.05 \mathrm{M} \mathrm{NaCl}$ to ensure a concentration low enough to allow for the observation of inhibition effects. A three-electrode cell was used to perform the analysis, with a platinum wire as the counter electrode and SCE as the reference electrode. The working electrode area was $0.626 \mathrm{~cm}^{2}$. For the EIS measurements, the systems were previously monitored for up to 96 hours. The amplitude of the EIS perturbation signal was $10 \mathrm{mV}$, and the frequency studied ranged from $100 \mathrm{kHz}$ to $10 \mathrm{mHz}$ using an frequency response analyzer model NOVA system and a potentiostat AUTOLAB PGSTAT 30.

Table 1. Description of the samples.

\begin{tabular}{ll}
\hline Sample & \multicolumn{1}{c}{ Description } \\
\hline FL & Tinplate reference, without hybrid film. \\
F1P60M & $\begin{array}{l}\text { Tinplate coated with hybrid film, thermally cured at } \\
60{ }^{\circ} \mathrm{C} . \text { Monolayered. }\end{array}$ \\
F1P60D & $\begin{array}{l}\text { Tinplate coated with hybrid film, thermally cured at } \\
60{ }^{\circ} \mathrm{C} . \text { Bilayered. }\end{array}$ \\
F1P90M & $\begin{array}{l}\text { Tinplate coated with hybrid film, thermally cured at } \\
90{ }^{\circ} \mathrm{C} \text {. Monolayered. } \\
\text { F1P90D }\end{array}$ \\
& $\begin{array}{l}\text { Tinplate coated with hybrid film, thermally cured at } \\
90{ }^{\circ} \mathrm{C} \text {. Bilayered. }\end{array}$ \\
\hline
\end{tabular}
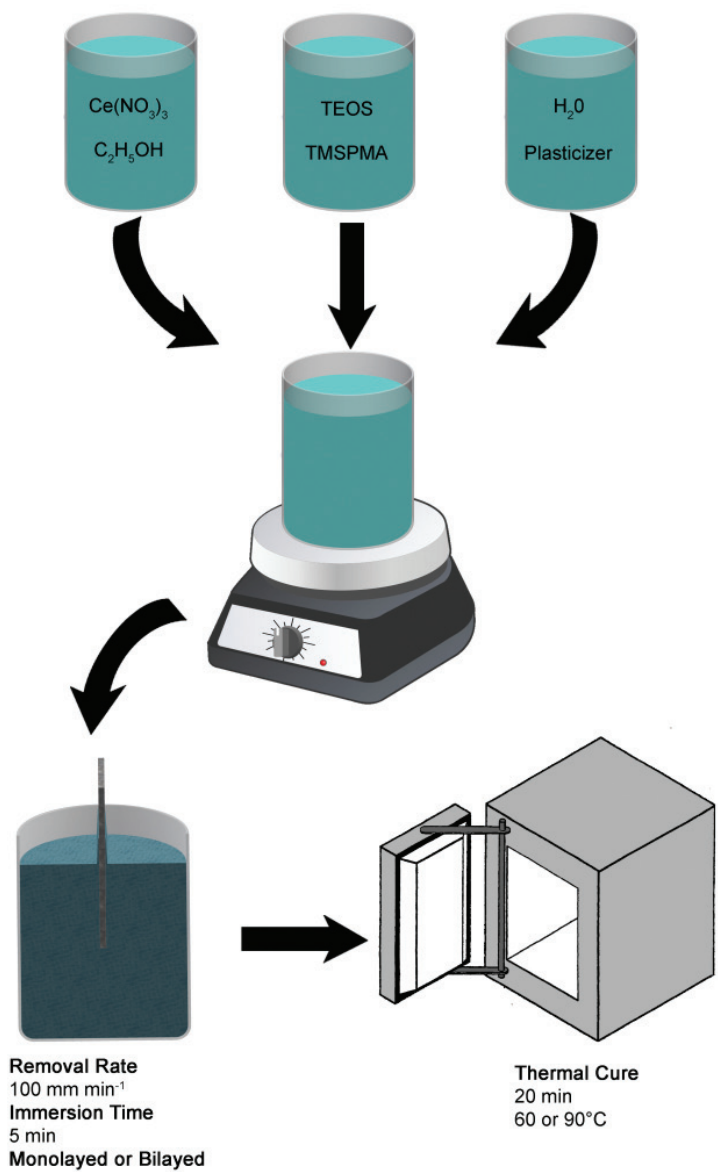

Figure 1. Experimental parameters of synthesis of the sols and processing to deposit coatings. 


\section{Results and Discussion}

\subsection{Morphological characterization}

Figure 2 shows the SEM micrographs for the hybrid films before the electrochemical tests. The samples F1P60D (Figure 2b) and F1P90M (Figure 2c) show the formation of a homogeneous and uncracked film. Furthermore, the curing temperature showed to be adequate for the monolayered system.

It was observed that the $60^{\circ} \mathrm{C}$-cured monolayered hybrid film was not cracked (Figure 2a). This is associated with a lower curing temperature which did not cause cracking; however, dark spots on the film can be observed, formed by non-evaporated retained solvent during the curing process. This is related to the addition of the plasticizer PEG 1500, due to its high molecular weight and increased viscosity, which limits the evaporation of volatile organic compounds during curing after application of the films ${ }^{16}$.

In the system F1P90D (Figure 2d) formation of cracks can be observed on the film. These results are in agreement with some researchers ${ }^{21,22}$ who report that a further increase of thickness, or an addition of a higher number of layers, would promote an improvement of the system against corrosion. However, the morphological analysis shows microcracks for the films exposed to high curing temperature, due to the fragile state of thicker layers, and a consequent decrease in corrosion resistance. Additionally, it is generally accepted that the cracked microstructure of the bilayered hybrid films is due to the drying stage ${ }^{23}$, because of the application of compressive stress during the crosslinking of the silane layer in the curing step ${ }^{24}$.

The layer thicknesses of the films determined by the analisys of cross section images obtained through SEM (Figure 3), as well as the results are shown in Table 2. The F1P60D and F1P90D bilayered samples had higher layer thickness values than monolayered systems, as it was expected. This result is associated to the fact that the first layer anchors the second one due to the presence of the PEG plasticizer in the sol formulation, since the organic phase allows better anchoring after the coating application ${ }^{25}$.

The results reported on Table 2 denote that the systems cured at $60^{\circ} \mathrm{C}$ had higher layer thickness values than the systems cured at $90^{\circ} \mathrm{C}$ for the same number of applied layers. This is in agreement with the results reported by

Table 2. Layer thicknesses for the hybrid films.

\begin{tabular}{ccc}
\hline Sample & Thickness $(\boldsymbol{\mu m})$ & Standard deviation $(\boldsymbol{\mu m})$ \\
\hline F1P60M & 0.98 & 0.11 \\
F1P60D & 1.95 & 0.10 \\
F1P90M & 0.73 & 0.08 \\
F1P90D & 1.71 & 0.12 \\
\hline
\end{tabular}

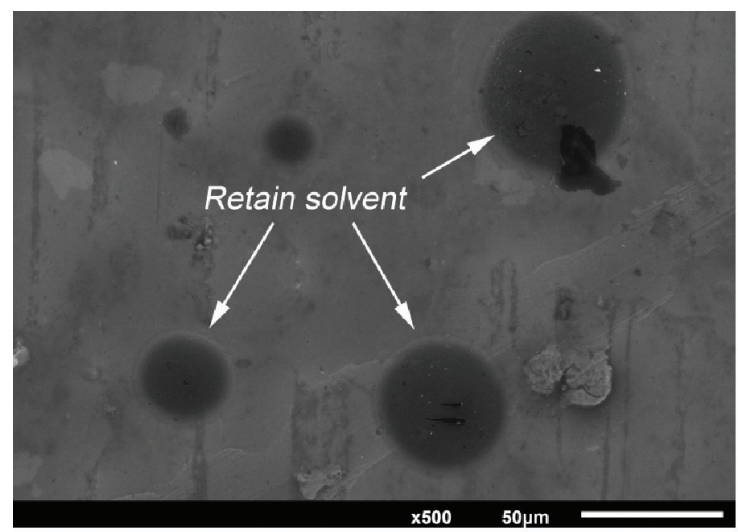

(a)

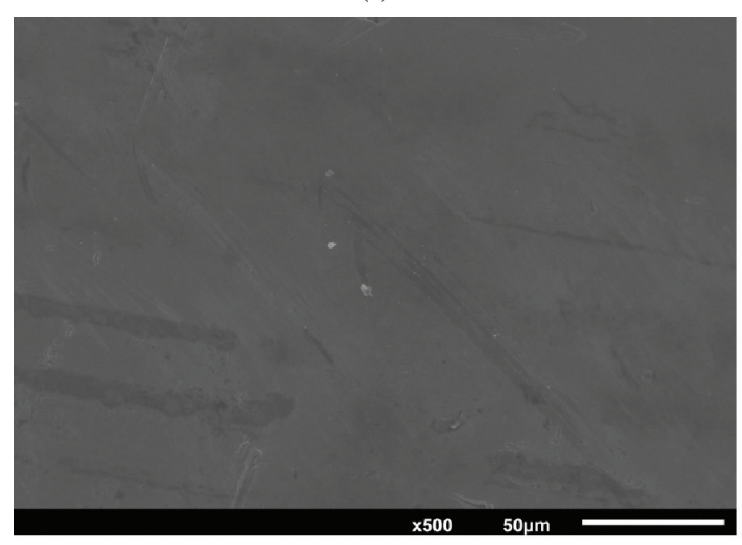

(c)

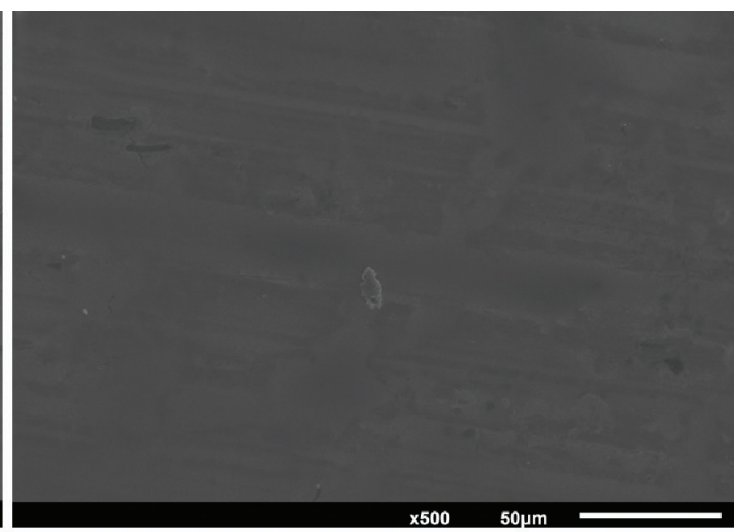

(b)

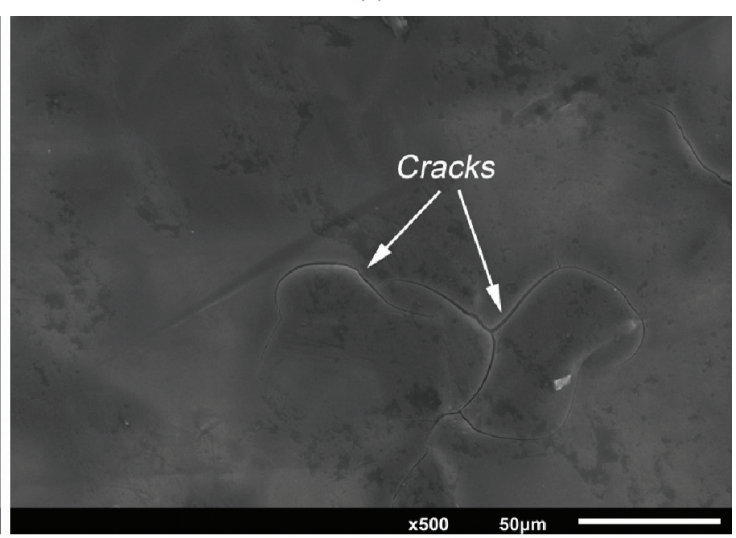

(d)

Figure 2. SEM micrographs obtained for the films: (a) F1P60M, (b) F1P60D, (c) F1P90M and (d) F1P90D. 


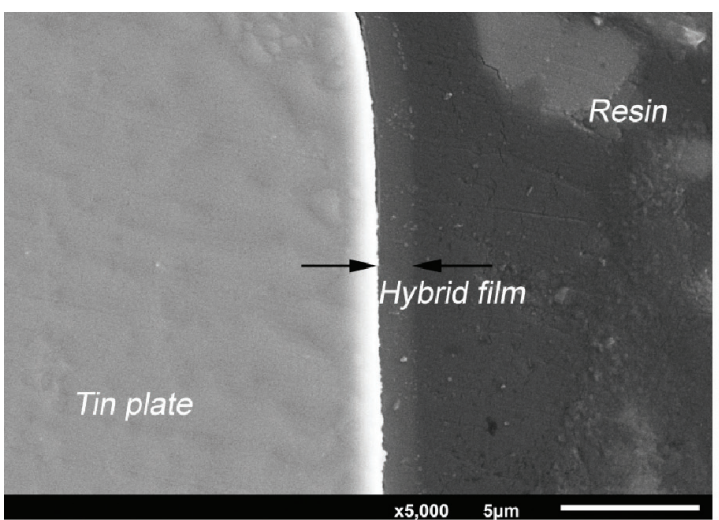

(a)

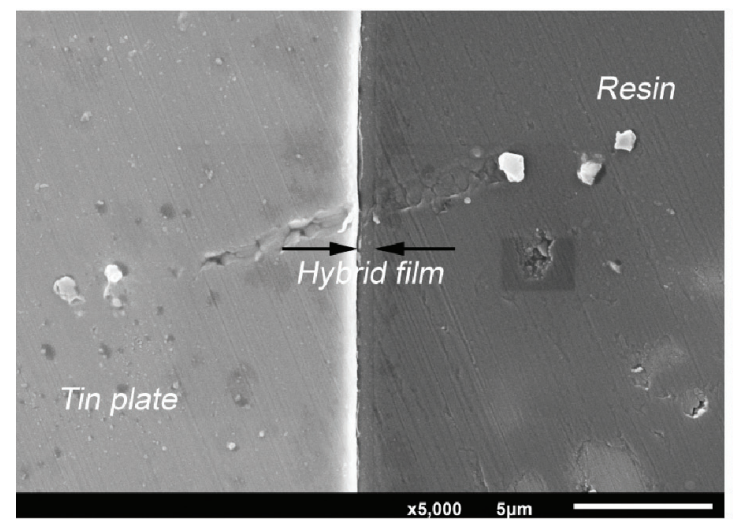

(c)

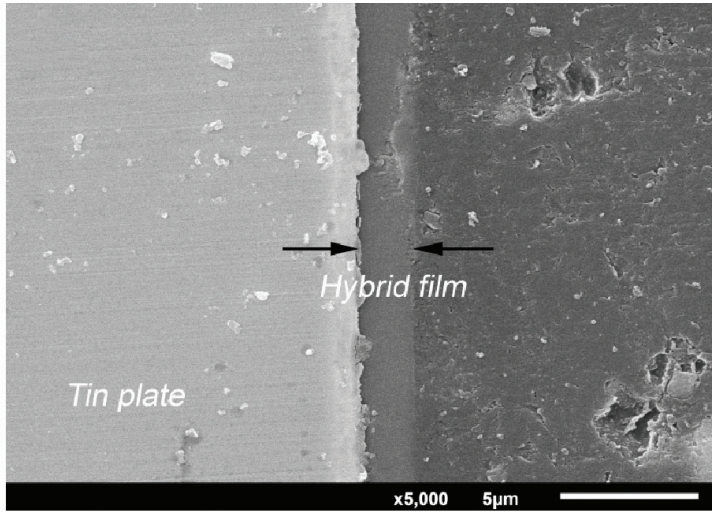

(b)

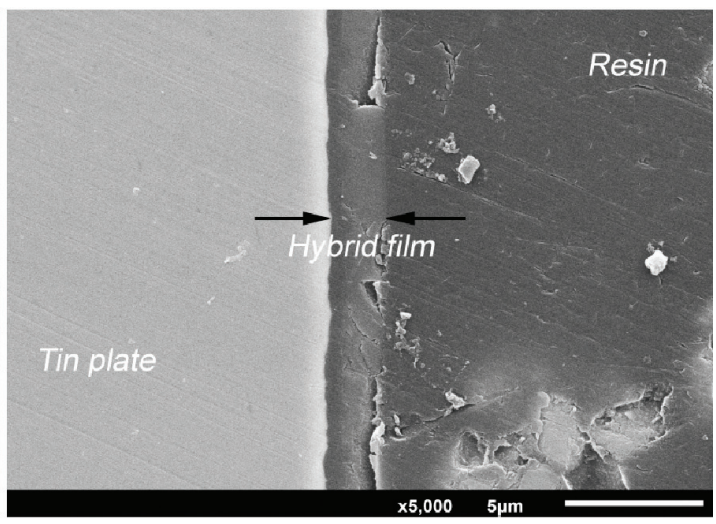

(d)

Figure 3. Layer thickness obtained for the hybrid films: (a) F1P60M, (b) F1P60D, (c) F1P90M and (d) F1P90D.

other authors ${ }^{26,27}$ whose works show that the curing process contributes to the good formation and performance of the silane film, as well as to the reduction of the layer thickness.

Besides, sample F1P60D (Figure 3b) had a denser, thicker and more compact film with perfect adhesion of the two layers, than the F1P90D system (Figure 3d). This is associated to the fact that the excess of heat in the silane curing process causes an increase in the crosslinking reactions, reducing their reactivity, which is due to the silane-siloxane conversion. Consequently, the film gets denser and the reaction and/or adhesion with subsequent layers gets harder ${ }^{28}$.

Despite the fact that the F1P90M sample has shown a lower thickness value than the F1P60M sample, the former showed a more compact, uniform and probably denser layer. These results are consome with other researchers ${ }^{29,30}$, in regards to the fact that silane layers improves the barrier properties by the dense reticulation, which forms a less porous layer, thus enhancing the corrosion protection.

\subsection{Contact angle}

From Table 3 it is possible to observe the contact angle measurements obtained for the studied systems and for the tinplate substrates (FL)

The F1P60D sample showed the highest contact angle value for the studied systems. This result proves that the higher the thickness of the layer is, the more difficult is the
Table 3. Contact angle values obtained by the sessile drop method.

\begin{tabular}{ccc}
\hline Sample & Contact angle & Standard deviation \\
\hline F1P60M & $73^{\circ}$ & 1.40 \\
F1P60D & $88^{\circ}$ & 1.18 \\
F1P90M & $82^{\circ}$ & 1.79 \\
F1P90D & $76^{\circ}$ & 1.13 \\
FL & $73^{\circ}$ & 1.90 \\
\hline
\end{tabular}

water penetration in denser layers which are completely polymerized, as it has been previously observed in relation to to the perfect adhesion of the two layers. Thus, the pore volume being smaller, water cannot permeate the structure and the formation of more hydrophobic films occurs ${ }^{15}$. Moreover, the $90^{\circ} \mathrm{C}$-cured bilayered system did not show a high contact angle value, perhaps due to the fact that the system was cracked, as observed in the SEM micrographs (Figure 2d) and so water could have penetrated in the cracks.

Comparing the monolayered systems, the $90^{\circ} \mathrm{C}$-cured system showed a higher contact angle value than the F1P60M sample. This can be associated with the fact that a higher curing temperature not only enhances the barrier properties, due to the formation of a less porous layer given the dense reticulation, but also obstructs the passage of water, and makes the film more hydrophobic.

For tinplate substrates (FL), the observed hydrophobicity is attributed to the presence of tin oxides ( $\mathrm{SnOx})$, such as 
$\mathrm{SnO}, \mathrm{SnO}_{2}$ and due to the fact that their hydrated forms provide complete or partial surface coverage.

\subsection{Fourier Transform Infrared Spectroscopy Analysis (FTIR)}

The FTIR spectra of the hybrid films prepared with different temperatures $\left(60^{\circ} \mathrm{C}\right.$ and $\left.90^{\circ} \mathrm{C}\right)$ are presented on Figure 4 and Table 4. As seen in Figure 4, the strong bands, between 1000 and $1200 \mathrm{~cm}^{-1}$, are attributed to $\mathrm{Si}-\mathrm{O}-\mathrm{Si}$, the structural backbone of the hybrid material. The formation of the $\mathrm{Si}-\mathrm{O}-\mathrm{Si}$ layer protects the tinplate substrate. The bands at intermediate frequencies, between 900 and $960 \mathrm{~cm}^{-1}$, arise from the $\mathrm{SiOCH}_{2} \mathrm{CH}_{3}$ group due to the incomplete hydrolysis of the TEOS. Peaks at approximately $2900 \mathrm{~cm}^{-1}$ were identified and associated with symmetrical and asymmetrical $\mathrm{CH}$ stretching $\left(\mathrm{CH}_{2}\right.$ and $\left.\mathrm{CH}_{3}\right)$ in the aliphatic chain of the organosilane (TMSPMA). These peaks are present in the totality of the prepared hybrids films, suggesting that the temperature does not influence the formation of the hybrid film, indicating full hydrolysis and a subsequent crosslinking of these samples. The broad absorption, between $3200 \mathrm{~cm}^{-1}$ and $3700 \mathrm{~cm}^{-1}$, is characteristic of the axial deformation of $\mathrm{OH}$, which could arise from silanol groups $(\mathrm{Si}-\mathrm{OH})$ that were not condensed during the synthesis. In this case, the intensity of the peaks on the two samples was very similar, showing that a temperature of $60^{\circ} \mathrm{C}$ was sufficient for crosslinking reactions. The bands close to 1728 and $1622 \mathrm{~cm}^{-1}$ are associated with the stretching vibrations of $\mathrm{C}=\mathrm{O}$ and $\mathrm{C}=\mathrm{C}$ groups, respectively.

\subsection{Electrochemical characterization}

Open circuit potential $\left(E_{\mathrm{OC}}\right)$ monitoring was conducted using an $\mathrm{NaCl} 0.05 \mathrm{M}$ solution in order to verify the potential variation with time. The curves are shown in Figure 5. In comparison to the uncoated sample (FL), all hybrid films shifted their potential towards the positive direction, which is due to the formation of a barrier between the substrate and the electrolyte.

As shown on Figure 5, the potential of the F1P60D hybrid film shifted to the positive direction compared to uncoated tinplate, or these samples presented a value of corrosion potential more noble than the substrate, indicating an improvement in corrosion resistance ${ }^{31}$. This result is related to the fact that the first layer has enabled a better adhesion of the second layer due to the presence of the PEG plasticizer in the sol formulation, which allows better anchoring of the coating to be applied later, and the temperature of $60^{\circ} \mathrm{C}$, which is low enough to enable a complete crosslinking, as shown in the FTIR results (Figure 4), allowing the adhesion of subsequent layers.

On the other hand, sample F1P90D did not show such nice performance. Despite being formed by two layers, these did not interact to one another, which resulted in cracking when the second layer was being formed (Figure 2d).

Table 4. FTIR peaks assignment as function of peak position ${ }^{28}$.

\begin{tabular}{ll}
\hline \multicolumn{1}{c}{ Peak position $\left(\mathbf{c m}^{-1}\right)$} & \multicolumn{1}{c}{ Peak assignment } \\
\hline 590 & $\mathrm{C}-\mathrm{H}\left(\mathrm{Si}-\mathrm{CH}_{2}-\mathrm{CH}_{2}-\mathrm{Si}\right)$ stretch \\
950 & $\begin{array}{l}\text { Asymmetrical stretching } \mathrm{Si}-\mathrm{O}-\mathrm{C}_{2} \mathrm{H}_{5} \\
\text { groups unhydrolyzed }\end{array}$ \\
& Si-O stretching of $\mathrm{Si}-\mathrm{O}-\mathrm{Si}$ crosslinked \\
1100 & $\mathrm{CH}_{2}$ and $\mathrm{CH}_{3}$ scissoring \\
1450 & $\mathrm{C}=\mathrm{C}-\mathrm{H}$ axial deformation \\
1635 & $\mathrm{C}=\mathrm{O}$ axial deformation \\
1700 & $\mathrm{C}-\mathrm{H}\left(\mathrm{CH}_{2}\right.$ e $\left.\mathrm{CH}_{3}\right)$ symmetric and \\
2900 & asymmetric stretch \\
& Axial deformation of $\mathrm{Si}-\mathrm{OH}$ group $\mathrm{OH}$ \\
3425 &
\end{tabular}

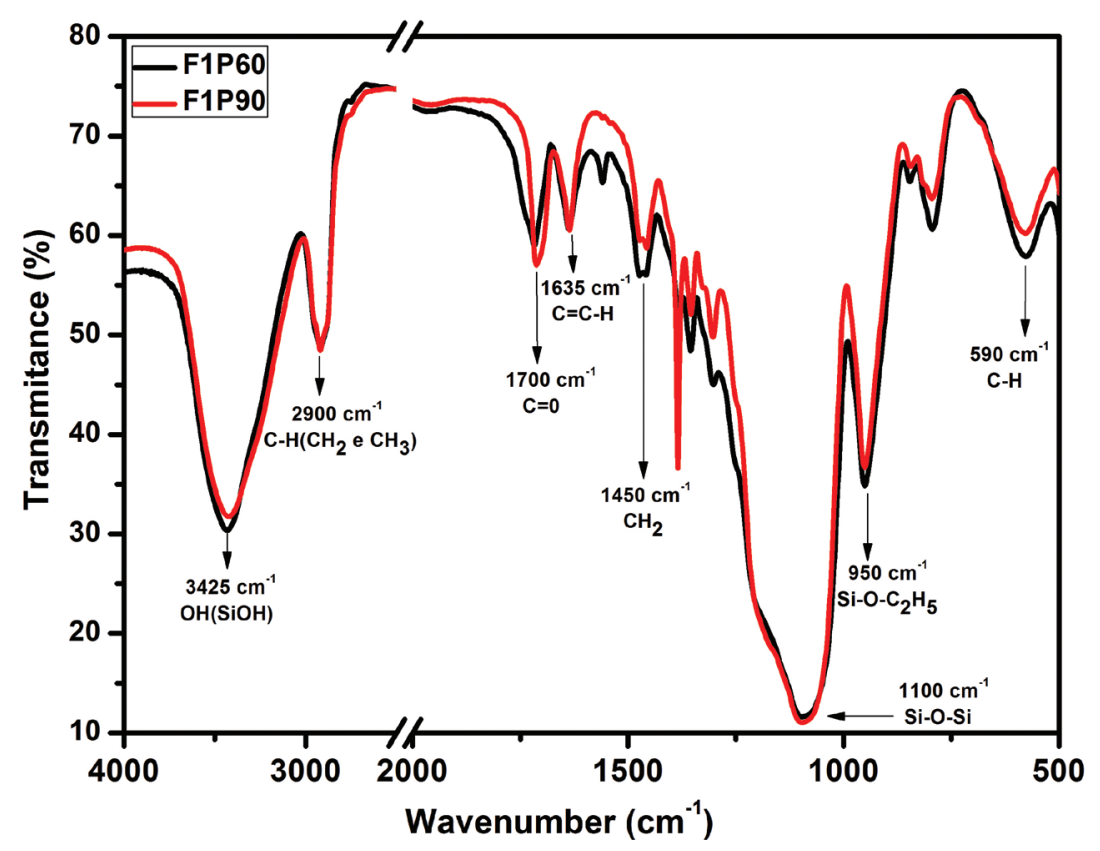

Figure 4. FTIR spectra of the hybrid films formulated with the different temperatures (F1P60 and F1P90). 
Consequently, cracks became preferential pathways for the electrolyte, thus reducing the film corrosion resistance.

Furthermore, it is remarkable that the F1P60M sample presented a potential close to that of uncoated tinplate, matching the behavior of these hydrophilic coatings with their contact angle value (Table 3). Also, formed by nonevaporated retained solvent during the curing process were present in the formation of these hybrid films, as shown by SEM micrographs (Figure 2a), that constitute a preferential pathway to electrolyte permeation.

Figure 6 presents the Nyquist diagrams, obtained by electrochemical impedance assay for the F1P60M, F1P60D, F1P90M and F1P90D films, as well as for the uncoated tinplate, performed in 24 and 96 hours in a solution of $0.05 \mathrm{M} \mathrm{NaCl}$.

From the mentioned diagrams (Figure 6), it is possible to observe that although the curves are similar in shape, they differ in magnitude. Therefore, the same fundamental phenomenon could have occurred in all these coatings but over a different effective area in each case. The diameter of the arc can be regarded as the polarization resistance $\left(R_{\mathrm{p}}\right)$ of the sample ${ }^{32}$.
All hybrid films coated samples showed a larger semicircle related to uncoated tinplate, demonstrating the protective action of these hybrids films. The performance of the samples is associated with the fact that a small increase in the branching of the ethylene oxide $\left(20\right.$ g.L $\left.\mathrm{L}^{-1}\right)$ radical was sufficient to decrease the rate of the condensation reaction in the triorganosilane groups. The condensation of the tetrafunctional alkoxides was also retarded in the presence of this monomer (PEG) due to the increased steric hindrance in the transition state. Therefore, a more flexible film was obtained with better adhesion to the substrate and hence an improvement in the anticorrosive properties of this coating ${ }^{33}$.

The high resistance of the F1P90M sample, after 24 hours of immersion (Figure 6a), is most likely due to the fact that this system had a more compact, uniform and less porous layer, causing an improvement in the corrosion protection. However, the resistance, the phase angle, and the impedance modulus of this system lowered significantly from 24 to 96 hours of immersion (Figure $6 \mathrm{~b}$ and Figure $7 \mathrm{~b}$ ). This result reveals the fragility of these coatings, allowing the permeation of the electrolyte through the film, perhaps because of the smaller layer thickness (Figure 3 and Table 2)

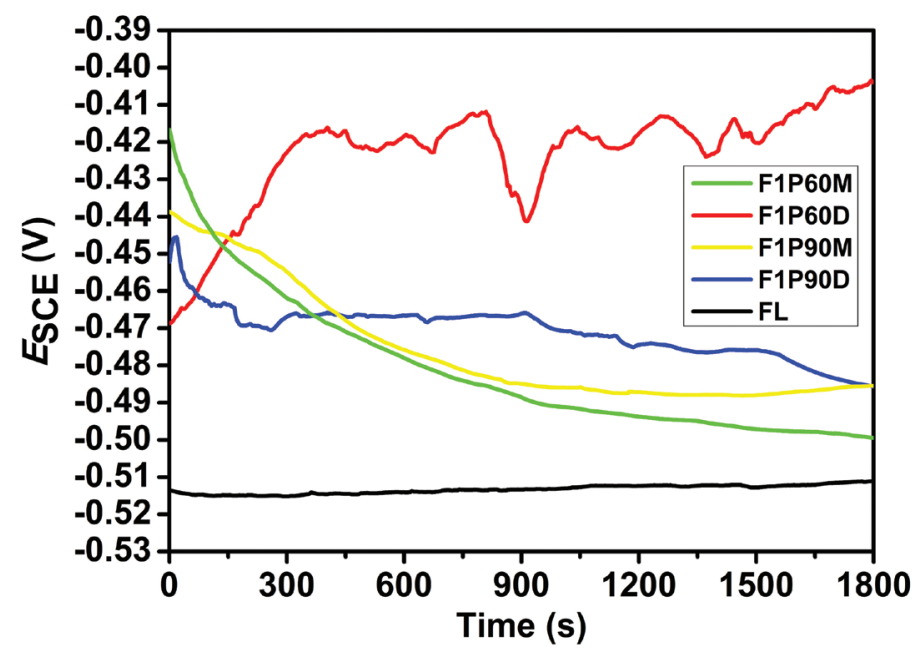

Figure 5. Open circuit potential (OCP) monitoring for all the hybrid films and the uncoated tinplate.

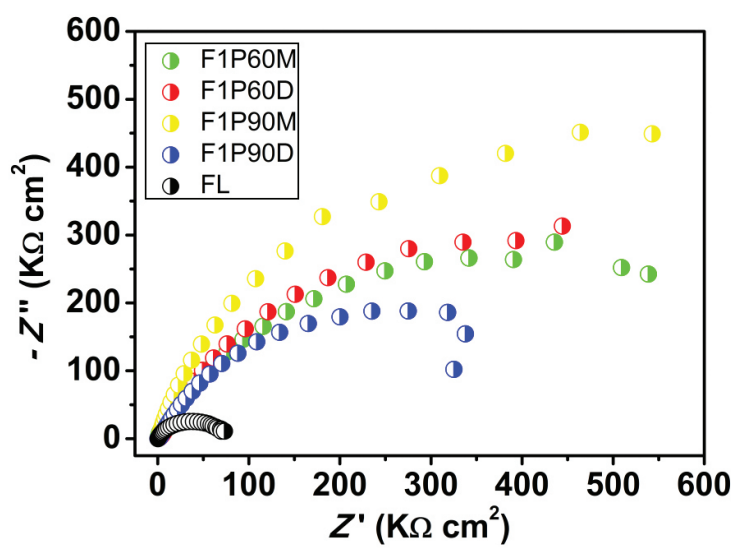

(a)

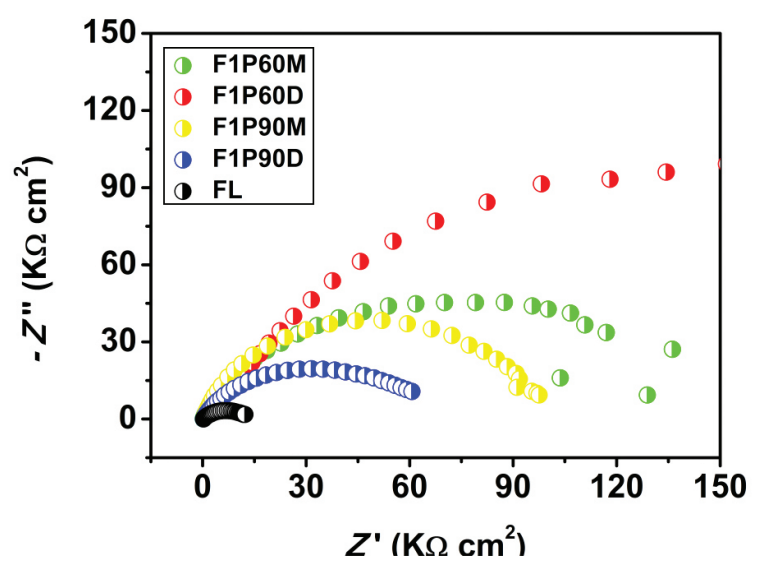

(b)

Figure 6. Nyquist plots obtained for hybrid film coated and uncoated tinplate in $0.05 \mathrm{M} \mathrm{NaCl}$ solution: (a) 24 and (b) 96 hours of immersion. 
between the studied films, thus not resisting to long periods of immersion.

As shown on the F1P60D sample, a bilayered coating helped to improve the protective performance of the hybrid film, as suggested by the highest resistance and impedance modulus values after 96 hour of testing (Figure $6 \mathrm{~b}$ and Figure $7 b$ ). There was an excellent adhesion between the layers, producing a denser, more compact and uncracked film, as per the SEM micrographs (Figure 2b), with a high layer thickness value (Figure $3 b$ ). These results are in agreement with studies conducted by Van Ooij et al. ${ }^{17}$, who demonstrated that a monolayered silane film is not enough to produce a good corrosion protection to a metallic substrate. Hence, a bilayered film coating on the metallic substrate is suggested, involving a two-step treatment.

The bilayered sample cured $90^{\circ} \mathrm{C}$ had the worst electrochemical impedance results after 96 hours of immersion. This may be associated to the fact that the F1P90D sample developed cracks on the film, as seen on the SEM images (Figure 2d). Therefore, the number of layers must be adjusted to the film curing temperature, for the increase of the film thickness (Figure 3 and Table 2) was not related to an improvement against corrosion. However, the chosen temperature which lead to the formation of cracks due to the embrittlement of the thickest layers, hence the reduction in corrosion resistance ${ }^{34}$.

The EIS was used in the present work to characterize the corrosion behavior of the developed coatings. A more detailed interpretation of the EIS measurements was performed by fitting the experimental plots using equivalent electrical circuit models which simulated the electrochemical behavior of the coatings (Figure 8). These models were based on the combination of resistances, capacitances, and other elements that should have a physical meaning, in relation to the electrochemical response of the system. In this work two equivalent electrical circuit models were used, and they were shown in Figure 8.

Tables 5-8 demonstrates the electrical parameter values obtained by fitting the equivalent electrical circuit from the experimental EIS data, obtained for the F1P60M,

\section{After 24 hours of immersion}
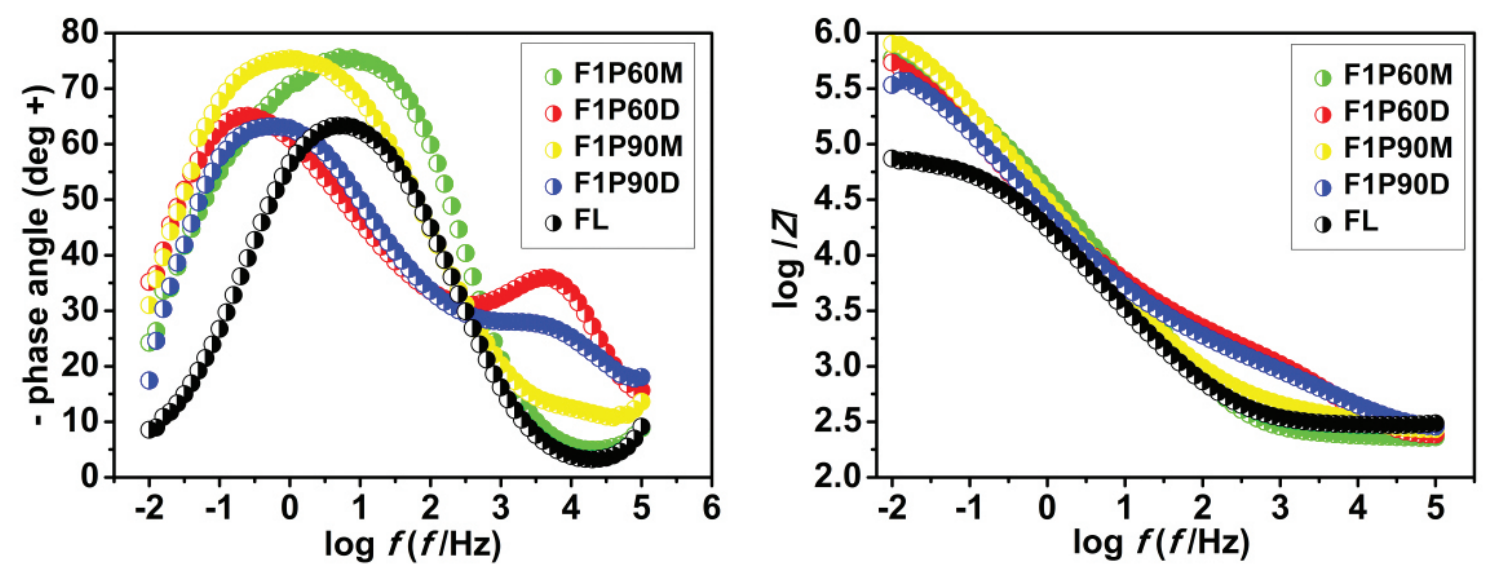

\section{After 96 hours of immersion}
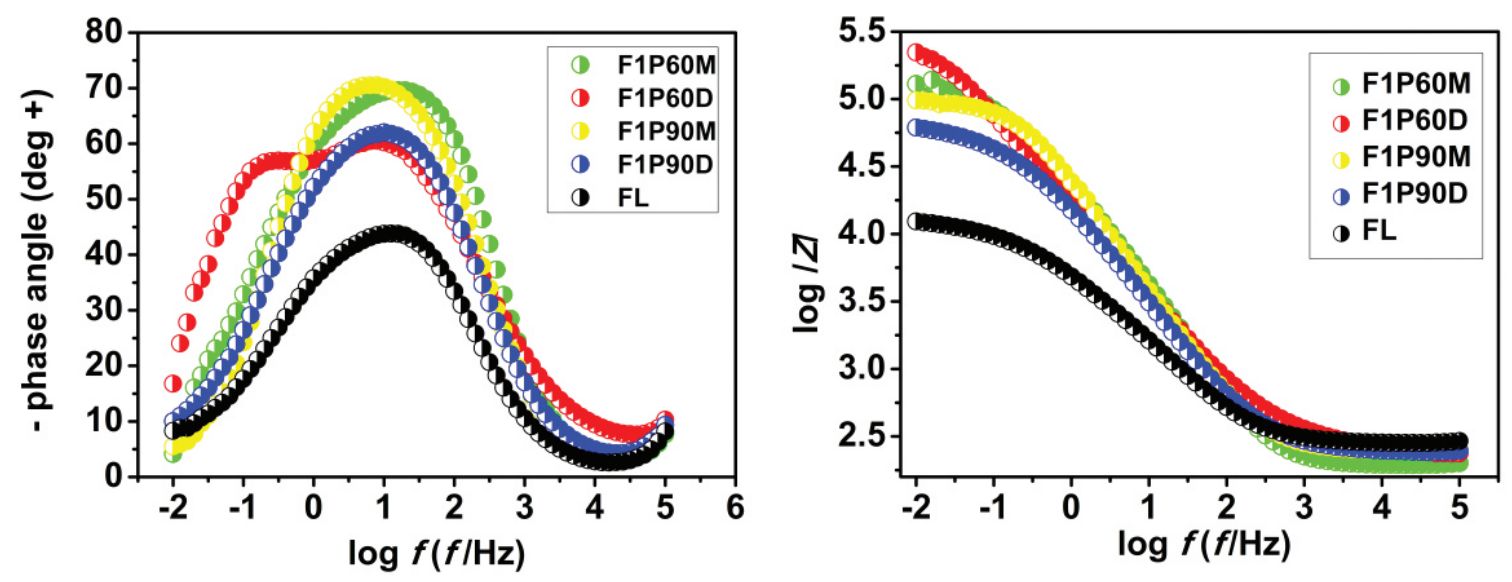

Figure 7. Bode plots obtained for hybrid film coated and uncoated tinplate in $0.05 \mathrm{M} \mathrm{NaCl}$ solution. 


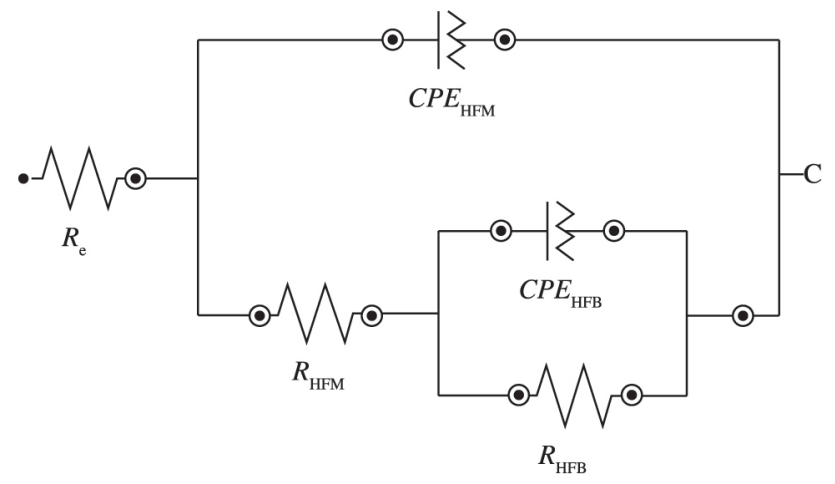

(a)

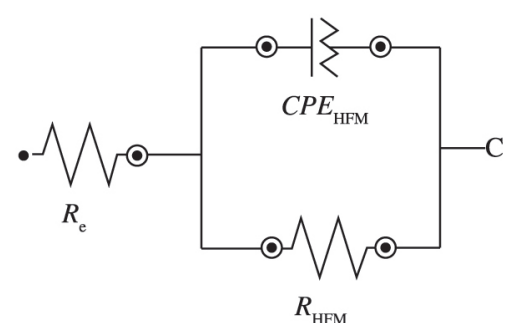

(b)

Figure 8. Equivalent circuit (a) samples F1P60D (at all times studied) and F1P90D (only up to 1 hour); (b) samples F1P60M and F1P90M (at 96 hours of immersion).

Table 5. Electrical elements fitted values for F1P60M film up to $96 \mathrm{~h}$ of immersion in $0.05 \mathrm{M} \mathrm{NaCl}$ solution. The error \% associated with each parameter value is given in parenthesis.

\begin{tabular}{|c|c|c|c|c|}
\hline Time (hours) & $R_{\mathrm{e}}\left(\Omega \mathbf{c m}^{2}\right)$ & $R_{\mathrm{HFM}}\left(\mathrm{k} \Omega \mathbf{c m}^{2}\right)$ & $C P E_{\mathrm{HFM}}\left(\mu \mathrm{F} \mathrm{cm}^{2}\right)$ & $n_{\mathrm{HFM}}$ \\
\hline $1 \mathrm{~h}$ & $287(9.9)$ & $495(4.1)$ & $7.51(8.2)$ & $0.67(2.8)$ \\
\hline $48 \mathrm{~h}$ & 206 (1.6) & $410(3.0)$ & $6.36(1.9)$ & $0.84(0.5)$ \\
\hline $96 \mathrm{~h}$ & $187(1.5)$ & $124(2.3)$ & $8.85(2.2)$ & $0.81(0.6)$ \\
\hline
\end{tabular}

Table 6. Electrical elements fitted values for F1P60D film up to $96 \mathrm{~h}$ of immersion in $0.05 \mathrm{M} \mathrm{NaCl}$ solution. The error \% associated with each parameter value is given in parenthesis.

\begin{tabular}{|c|c|c|c|c|c|c|c|}
\hline Time (hours) & $R_{\mathrm{e}}\left(\Omega \mathbf{c m}^{2}\right)$ & $R_{\mathrm{HFM}}\left(\mathrm{k} \Omega \mathrm{cm}^{2}\right)$ & $C P E_{\mathrm{HFM}}\left(\mu \mathrm{F} \mathrm{cm}^{2}\right)$ & $n_{\mathrm{HFM}}$ & $R_{\mathrm{HFB}}\left(\mathrm{k} \Omega \mathrm{cm}^{2}\right)$ & $C P E_{\mathrm{HFB}}\left(\eta \mathrm{F} \mathrm{cm}^{2}\right)$ & $n_{\mathrm{HFB}}$ \\
\hline $1 \mathrm{~h}$ & $161(5.8)$ & $5.6(10.3)$ & $38.4(4.1)$ & $0.85(3.8)$ & $1420(9.3)$ & $6.2(2.0)$ & $0.58(1.6)$ \\
\hline $48 \mathrm{~h}$ & $275(5.3)$ & $44.9(6.7)$ & $0.21(4.7)$ & 0.95 (1.7) & 209 (3.8) & $1.5(5.3)$ & $0.80(4.9)$ \\
\hline $96 \mathrm{~h}$ & $239(1.5)$ & $32.0(6.1)$ & $0.27(8.9)$ & $0.63(3.3)$ & $251(6.2)$ & $0.2(7.8)$ & $0.88(7.7)$ \\
\hline
\end{tabular}

Table 7. Electrical elements fitted values for F1P90M film up to $96 \mathrm{~h}$ of immersion in $0.05 \mathrm{M} \mathrm{NaCl}$ solution. The error \% associated with each parameter value is given in parenthesis.

\begin{tabular}{|c|c|c|c|c|}
\hline Time (hours) & $R_{\mathrm{e}}\left(\Omega \mathbf{c m}^{2}\right)$ & $R_{\mathrm{HFM}}\left(\mathrm{k} \Omega \mathrm{cm}^{2}\right)$ & $C P E_{\mathrm{HFM}}\left(\mu \mathrm{F} \mathrm{cm}^{2}\right)$ & $n_{\mathrm{HFM}}$ \\
\hline $1 \mathrm{~h}$ & $247(4.3)$ & $1200(5.1)$ & $8.7(8.4)$ & $0.58(3.1)$ \\
\hline $48 \mathrm{~h}$ & $274(1.3)$ & $651(2.3)$ & $6.9(1.4)$ & $0.84(0.4)$ \\
\hline $96 \mathrm{~h}$ & $248(0.7)$ & $98.8(1.1)$ & $8.1(1.2)$ & $0.84(0.3)$ \\
\hline
\end{tabular}

Table 8. Electrical elements fitted values for F1P90D film up to $96 \mathrm{~h}$ of immersion in $0.05 \mathrm{M} \mathrm{NaCl}$ solution. The error \% associated with each parameter value is given in parenthesis.

\begin{tabular}{cccccccc}
\hline Time (hours) & $\boldsymbol{R}_{\mathrm{e}}\left(\Omega \mathbf{c m}^{2}\right)$ & $\boldsymbol{R}_{\mathrm{HFM}}\left(\mathbf{k} \Omega \mathbf{~ c m}^{2}\right)$ & $\boldsymbol{C P} \boldsymbol{E}_{\mathrm{HFM}}\left(\boldsymbol{\mu} \mathbf{F ~ \mathbf { ~ m } ^ { 2 } )}\right.$ & $\boldsymbol{n}_{\mathrm{HFM}}$ & $\boldsymbol{R}_{\mathrm{HFB}}\left(\mathbf{k} \Omega \mathbf{~ c m}^{2}\right)$ & $C P E_{\mathrm{HFB}}\left(\boldsymbol{\mu} \mathbf{F ~ \mathbf { ~ m } ^ { 2 } )}\right.$ & $\boldsymbol{n}_{\mathrm{HFB}}$ \\
\hline $1 \mathrm{~h}$ & $171(3.4)$ & $851(3.4)$ & $6.93(0.9)$ & $0.73(0.9)$ & $10.3(3.8)$ & $2.1(5.9)$ & $0.62(1.0)$ \\
$48 \mathrm{~h}$ & $327(3.4)$ & $281(9.0)$ & $12.7(4.1)$ & $0.69(1.4)$ & & & \\
$96 \mathrm{~h}$ & $240(1.0)$ & $61(1.6)$ & $15.2(1.7)$ & $0.74(0.5)$ & & & \\
\hline
\end{tabular}

F1P60D, F1P90M, and F1P90D hybrid films, for 96 hours of immersion in a $0.05 \mathrm{M} \mathrm{NaCl}$ solution. The values indicated in brackets on Tables 5-8 show that there were less than $10 \%$ (less than $5 \%$ in most cases) of errors involved in the fitting procedure.

In several circuits the capacitance was substituted by a $C P E$ in order to take into account the non-ideality of the systems. In these circuits (Figure 8a), Re represents the electrolyte resistance, $R_{\mathrm{HFM}}$ and $C P E_{\mathrm{HFM}}$ represent, respectively, the resistance and a constant phase element associated to the electrolyte permeation resistance through the monolayered hybrid film. In the same circuit, $R_{\mathrm{HFB}}$ and $C P E_{\mathrm{HFB}}$ represent the resistance and a constant phase element indicating the effect of electrolyte permeation resistance through the bilayered hybrid film.

The same equivalent circuit model (Figure 8a) was used for the electrochemical behavior simulation in all of the studied immersion times (1, 24, 48, 72 and 96 hours) for the 
F1P60D sample, and just for the immersion time of 1 hour for the F1P90D sample. This behavior has been observed by the other authors ${ }^{35,36}$, and this model confirms that a monolayered film is not enough to produce a good corrosion protection to the substrate. Indeed, it is recommended that metallic substrates must be coated with bilayered films in order to enhance the corrosion protection, avoiding cracks and delamination problems. The F1P60D hybrid film resistance $\left(R_{\mathrm{HFB}}\right)$ could be estimated by the Nyquist diagram at the end of the experiment (Figure 6b), taking into account the highest semicircle diameter at high frequency ranges. The RT (monolayered system resistance + bilayered system resistance) values were found to be around $251 \mathrm{k} \Omega \mathrm{cm}^{2}$ for the 96 hours of immersion (Table 6).

In the circuits shown on Figure $8 b$, Re represents the electrolyte resistance, $R_{\mathrm{HFM}}$ and CPEHFM represent,

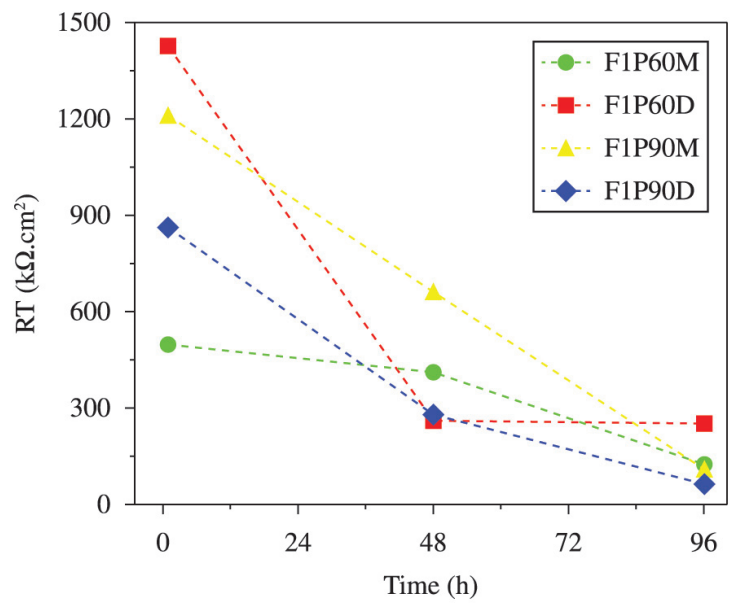

Figure 9. Evolution of the hybrid films resistance for F1P60M, F1P60D, F1P90M and F1P90D in a $0.05 \mathrm{M} \mathrm{NaCl}$ solution with the immersion time. respectively, the resistance and a constant phase element associated to the effect of electrolyte permeation resistance through the monolayered hybrid film. The same equivalent circuit model (Figure 8b) was used for the electrochemical behavior simulation at all immersion times studied $(1,24$, 48, 72 and 96 hours) for the F1P60M and F1P90M samples. Electrochemical behavior simulation for 24 hours of immersion was done in the F1P90D sample. This behavior was observed by other authors ${ }^{37-39}$ indicating the hybrid films which retards the corrosion processes on the tinplate surface.

Figure 9 shows the evolution of the coating properties - i.e., the total resistance, as a function of immersion time. Generally, the high-frequency resistance values indicated a decrease during the first hours of immersion, due to the development of conductive pathways inside the film ${ }^{40}$; occurring more significantly in the F1P60D, F1P90M and F1P90D hybrids films. It can be observed that the F1P60D sample presented the highest resistance values after 48 hours of immersion (Figure 9) in comparison to other samples (F1P60M, F1P90M and F1P90D). This can be associated to the high layer thickness value (Figure 3 and Table 2), and consequently, it can be said that the curing temperature of $60^{\circ} \mathrm{C}$, was enough to obtain a dense, hydrophobic film (as shown in the contact angle results - Table 3 - and in the FTIR results - Figure 4 and Table 4).

The evolution of the coating resistance is a major characteristic of the barrier properties of a protective layer ${ }^{41}$. The F1P90M and F1P90D samples presented a sharp reduction of the resistance values, which may be associated to the presence of cracks and irregularities in the formation of F1P90D shown by the SEM micrographs (Figure 2). The case of the F1P90M sample is due to the fragility of these coatings, allowing the permeation of the electrolyte through the film. This can be associated to the lower layer thickness value (Figure 3 and Table 2) and, consequently, not resisting to long periods of immersion.

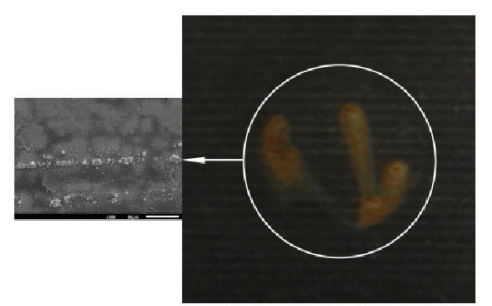

(a)

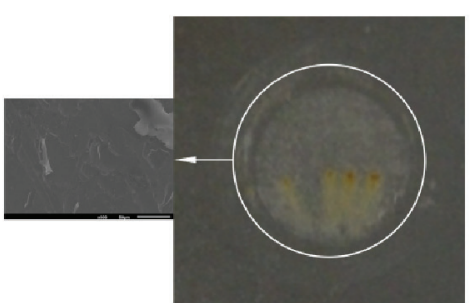

(b)

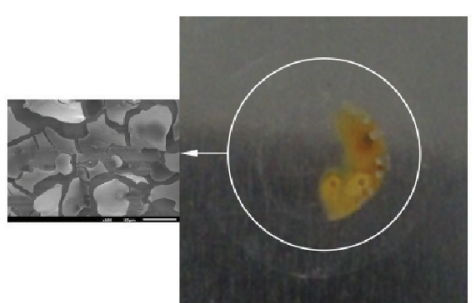

(c)

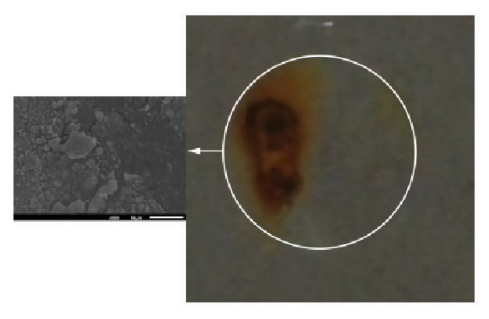

(d)

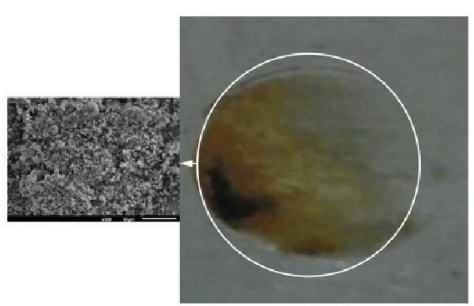

(e)

Figure 10. Images obtained for the samples: (a) F1P60M, (b) F1P60D, (c) F1P90M, (d) F1P90D and (e) FL after electrochemical impedance test. 
Figure 10 shows the SEM micrographs for the samples after 96 hours of electrochemical impedance assays in a $0.05 \mathrm{M} \mathrm{NaCl}$ solution. It can be observed that the F1P60D sample (Figure 10b) had less corrosion products, as it was expected regarding the good electrochemical performance showed by this system.

\section{Conclusion}

The results showed that all the studied hybrid films: F1P60M, F1P60D, F1P90M and F1P90D, presented an increase in the corrosion resistance when compared to the uncoated tinplate.

For the monolayered samples, the $90^{\circ} \mathrm{C}$-cured system showed a lower layer thickness, however, not only the layer was more compact, more uniform and less porous, but it also had a better electrochemical performance at the end of the electrochemical impedance test than the $60^{\circ} \mathrm{C}$-cured one.

As for the bilayered samples, the $60^{\circ} \mathrm{C}$-cured system had a better electrochemical performance in comparison to the $90^{\circ} \mathrm{C}$-cured bilayer system. This behavior is associated to

\section{References}

1. Xia DH, Wang JH, Song SZ, Zhong B and Han ZW. The corrosion behavior of lacquered tinplate in functional beverage. Advanced Materials Research. 2011; 233-235:1747-1751. http://dx.doi.org/10.4028/www.scientific.net/AMR.233235.1747

2. Zumelzu E and Cabezas C. Observations on the influence of microstructure on electrolytic tinplate corrosion. Materials Characterization. 1995; 34(2):143-148. http://dx.doi. org/10.1016/1044-5803(94)00060-X

3. Chen S, Xie L and Xue F. X-ray photoelectron spectroscopy investigation of commercial passivated tinplate surface layer. Applied Surface Science, 2013; 276:454-457. http://dx.doi. org/10.1016/j.apsusc.2013.03.115

4. Martins JI. Corrosion problems in tinplate cans for storing contact glues for shoes. Engineering Failure Analysis. 2012; 26:258-265. http://dx.doi.org/10.1016/j. engfailanal.2012.08.003

5. Cabral AM, Trabelsi W, Serra R, Montemor MF, Zheludkevich ML and Ferreira MGS. The corrosion resistance of hot dip galvanised steel and aa2024-t 3 pre-treated with bis[triethoxysilylpropyl] tetrasulfide solutions doped with ce(no3)3. Corrosion Science. 2006; 48(11):3740-3758. http:// dx.doi.org/10.1016/j.corsci.2006.01.010

6. Rosalbino F, Scavino G, Mortarino G, Angelini E and Lunazzi G. EIS study on the corrosion performance of a $\mathrm{Cr}(\mathrm{III})$-based conversion coating on zinc galvanized steel for the automotive industry. Journal of Solid State Electrochemistry. 2010; 15(4):703-709. http://dx.doi.org/10.1007/s10008-010-1140-7

7. Huang X, Li N, Wang H, Sun H, Sun S and Zheng J. Electrodeposited cerium film as chromate replacement for tinplate. Thin Solid Films. 2008; 516(6):1037-1043. http:// dx.doi.org/10.1016/j.tsf.2007.08.044

8. Nincević Grassino A, Grabarić Z, Pezzani A, Fasanaro G and Lo Voi A. Influence of essential onion oil on tin and chromium dissolution from tinplate. Food and Chemical Toxicology. 2009; 47(7):1556-1561. PMid:19362114. http://dx.doi.org/10.1016/j. fct.2009.04.003 the high layer thickness obtained for this film, as well as to the formation of a homogeneous, uncracked, and continuous film, and a higher contact angle value. The temperature of $60^{\circ} \mathrm{C}$ was enough to obtain a dense, hydrophobic film and a higher corrosion resistance at the end of the electrochemical impedance test, in comparison with all of the other samples.

The $90^{\circ} \mathrm{C}$-cured bilayer system showed a worse corrosion resistance when compared to the $90^{\circ} \mathrm{C}$-cured monolayered system, to the $60^{\circ} \mathrm{C}$-cured bilayer and also to the other monolayered samples. This is associated to the presence of cracks and irregularities in the formation of the hybrid film.

\section{Acknowledgements}

The authors would like to express their gratitude for the financial support of CAPES (a Brazilian Governmental agency for the development of human resources) and CNPq (the Brazilian National Council for Scientific and Technological Development).

9. Dalmoro V, Santos JHZ and Azambuja DS. Corrosion behavior of aa2024-t3 alloy treated with phosphonate-containing teos. Journal of Solid State Electrochemistry. 2011; 16(1):403-414. http://dx.doi.org/10.1007/s10008-011-1346-3

10. $\mathrm{Hu} \mathrm{H}, \mathrm{Li} \mathrm{N}$, Cheng $\mathrm{J}$ and Chen L. Corrosion behavior of chromium-free dacromet coating in seawater. Journal of Alloys and Compounds. 2009; 472(1-2):219-224. http://dx.doi. org/10.1016/j.jallcom.2008.04.029

11. Wang D and Bierwagen GP. Sol-gel coatings on metals for corrosion protection. Progress in Organic Coatings. 2009; 64(4):327-338. http://dx.doi.org/10.1016/j. porgcoat.2008.08.010

12. Sanchez C, Julián B, Belleville P and Popall M. Applications of hybrid organic-inorganic nanocomposites. Journal of Materials Chemistry. 2005; 15(35-36):3559-3592. http:// dx.doi.org/10.1039/b509097k

13. Brinker CJ and Scherer GW. Sol-gel science: the physics and chemistry of sol-gel processing. Boston: Academic Press; 1990.

14. Kunst SR, Cardoso HRP, Oliveira CT, Silva Filho CI, Sarmento VHV, Menezes TL et al. Influence of tetraethoxysilane addition in siloxane - poly(methyl methacrylate) hybrid films applied on galvanized steel. International Journal Electrochemical Science. 2013; 8(10): 11984-12004.

15. Certhoux E, Ansart F, Turq V, Bonino JP, Sobrino JM, Garcia $\mathrm{J}$ et al. New sol-gel formulations to increase the barrier effect of a protective coating against the corrosion of steels. Progress in Organic Coatings. 2013; 76(1):165-172. http://dx.doi. org/10.1016/j.porgcoat.2012.09.002

16. Carvalho HWP, Suzana AF, Santilli CV and Pulcinelli SH. Structure and thermal behavior of PMMA-polysilsesquioxane organic-inorganic hybrids. Polymer Degradation and Stability. 2014; 104:112-119. http://dx.doi.org/10.1016/j. polymdegradstab.2014.03.031

17. Van Ooij WJ. Improved service life of coated metals by engineering the polymer-metal interface. In: Bauer DR and Martin JW, editors. Service life prediction of organic coatings. Washington: ACS; 1999. p. 354-377. ACS Symposium Series 722 . 
18. Malfatti CF, Menezes TL, Radtke C, Esteban J, Ansart F and Bonino JP. The influence of cerium ion concentrations on the characteristics of hybrid films obtained on aa2024-t3 aluminum alloy. Materials and Corrosion. 2012; 63(9):819-827.

19. Pan G, Schaefer DW and Ilavsky J. Morphology and water barrier properties of organosilane films: the effect of curing temperature. Journal of Colloid and Interface Science. 2006; 302(1):287293. PMid:16860812. http://dx.doi.org/10.1016/j. jcis.2006.06.031

20. Kozhukharov S, Kozhukharov V, Schem M, Aslan M, Wittmar M, Wittmar A et al. Protective ability of hybrid nanocomposite coatings with cerium sulphate as inhibitor against corrosion of AA2024 aluminium alloy. Progress in Organic Coatings. 2012; 73(1):95-103. http://dx.doi.org/10.1016/j. porgcoat.2011.09.005

21. Vanin FM, Sobral PJA, Menegalli FC, Carvalho RA and Habitante AMQB. Effects of plasticizers and their concentrations on thermal and functional properties of gelatinbased films. Food Hydrocolloids. 2005; 19(5):899-907. http:// dx.doi.org/10.1016/j.foodhyd.2004.12.003

22. Hansal WEG, Hansal S, Pölzler M, Kornherr A, Zifferer G and Nauer GE. Investigation of polysiloxane coatings as corrosion inhibitors of zinc surfaces. Surface and Coatings Technology. 2006; 200(9):3056-3063. http://dx.doi.org/10.1016/j. surfcoat.2005.01.049

23. Campestrini P, Van Westing EP and Wit JH. Influence of surface preparation on performance of chromate conversion coatings on Alclad 2024 aluminium alloy. Part II: EIS investigation. Electrochimica Acta. 2001; 46(17):2631-2647. http://dx.doi. org/10.1016/S0013-4686(01)00476-5

24. Luis EM and Palomino PHS. Investigation of the corrosion behaviour of a bilayer cerium-silane pre-treatment on $\mathrm{Al}$ 2024T3 in 0.1M NaCl. Electrochimica Acta. 2007; 52(27):74967505. http://dx.doi.org/10.1016/j.electacta.2007.03.002

25. Subramanian V and Van Ooij WJ. Silane based metal pretreatments as alternatives to chromating: shortlisted. Surface Engineering. 1999; 15(2):168-172. http://dx.doi. org/10.1179/026708499101516407

26. Franquet A, De Laet J, Schram T, Terryn H, Subramanian V, Van Ooij WJ et al. Determination of the thickness of thin silane films on aluminium surfaces by means of spectroscopic ellipsometry. Thin Solid Films. 2001; 384(1):37-45. http:// dx.doi.org/10.1016/S0040-6090(00)01805-8

27. Franquet A, Terryn $\mathrm{H}$ and Vereecken J. IRSE study on effect of thermal curing on the chemistry and thickness of organosilane films coated on aluminium. Applied Surface Science. 2003; 211(1-4):259-269. http://dx.doi.org/10.1016/ S0169-4332(03)00258-7

28. Romano AP, Fedel M, Deflorian F and Olivier MG. Silane sol-gel film as pretreatment for improvement of barrier properties and filiform corrosion resistance of 6016 aluminium alloy covered by cataphoretic coating. Progress in Organic Coatings. 2011; 72(4):695-702. http://dx.doi.org/10.1016/j. porgcoat.2011.07.012

29. Van Ooij WJ and Zhu D. Electrochemical impedance spectroscopy of bis-[triethoxysilypropyl]tetrasulfide on $\mathrm{Al}$
2024-T3 substrates. Corrosion. 2001; 57(5):413-427. http:// dx.doi.org/10.5006/1.3290365

30. Franquet A, Terryn $\mathrm{H}$ and Vereecken J. Composition and thickness of non-functional organosilane films coated on aluminium studied by means of infra-red spectroscopic ellipsometry. Thin Solid Films. 2003; 441(1-2):76-84. http:// dx.doi.org/10.1016/S0040-6090(03)00886-1

31. Tomachuk CR, Elsner CI, Sarli ARD and Ferraz OB. Morphology and corrosion resistance of $\mathrm{Cr}(\mathrm{III})$-based conversion treatments for electrogalvanized steel. Journal of Coatings Technology and Research. 2010; 7(4):493-502. http:// dx.doi.org/10.1007/s11998-009-9213-1

32. Gómez-Romero P and Sanchez C. Hybrid materials, functional applications: an introduction. In: Gómez-Romero P and Sanchez C. Functional hybrid materials. Weinheim: WileyVCH; 2005. p. 1-14. http://dx.doi.org/10.1002/3527602372. ch1

33. Ferreira $\mathrm{AO}$ and Brandão M. Guia prático da farmácia magistral. São Paulo: Pharmabooks; 2008.

34. Bastos AC, Ferreira MGS and Simões AMP. Effects of mechanical forming on the corrosion of electrogalvanised steel. Corrosion Science. 2013; 69:87-96. http://dx.doi.org/10.1016/j. corsci.2012.11.026

35. Guo X and An M. Experimental study of electrochemical corrosion behaviour of bilayer on az $31 \mathrm{~b} \mathrm{mg}$ alloy. Corrosion Science. 2010; 52(12):4017-4027. http://dx.doi.org/10.1016/j. corsci.2010.08.017

36. Garcia SJ, Markley TA, Mol JMC and Hughes AE. Unravelling the corrosion inhibition mechanisms of bi-functional inhibitors by eis and sem-eds. Corrosion Science. 2013; 69:346-358. http://dx.doi.org/10.1016/j.corsci.2012.12.018

37. Phanasgaonkar A and Raja VS. Influence of curing temperature, silica nanoparticles- and cerium on surface morphology and corrosion behaviour of hybrid silane coatings on mild steel. Surface and Coatings Technology. 2009; 203(16):2260-2271. http://dx.doi.org/10.1016/j.surfcoat.2009.02.020

38. Bajat JB, Milošev I, Jovanović Ž, Jančić-Heinemann RM, Dimitrijević M and Mišković-Stanković VB. Corrosion protection of aluminium pretreated by vinyltriethoxysilane in sodium chloride solution. Corrosion Science. 2010; 52(3): 10601069. http://dx.doi.org/10.1016/j.corsci.2009.11.035

39. Varma PCR, Colreavy J, Cassidy J, Oubaha M, McDonagh C and Duffy B. Corrosion protection of AA 2024-T3 aluminium alloys using 3, 4-diaminobenzoic acid chelated zirconiumsilane hybrid sol-gels. Thin Solid Films. 2010; 518(20):57535761. http://dx.doi.org/10.1016/j.tsf.2010.05.088

40. Montemor MF, Pinto R and Ferreira MGS. Chemical composition and corrosion protection of silane films modified with $\mathrm{CeO} 2$ nanoparticles. Electrochimica Acta. 2009; 54(22):5179-5189. http://dx.doi.org/10.1016/j. electacta.2009.01.053

41. Schem M, Schmidt T, Gerwann J, Wittmar M, Veith M, Thompson GE et al. CeO2-filled sol-gel coatings for corrosion protection of AA2024-T3 aluminium alloy. Corrosion Science. 2009; 51(10):2304-2315. http://dx.doi.org/10.1016/j. corsci.2009.06.007 